\title{
Placenta: Anatomía e Histología Comparada
}

\author{
Placenta; Compared Anatomy and Histology
}

${ }^{*, * *}$ Ignacio Roa; ${ }^{*, * * *}$ Carolina Smok S.; ${ }^{* * * *}$ Ruth Prieto G.

ROA, I.; SMOK, S. C. \& PRIETO, G. R. Placenta; anatomía e histología comparada. Int. J. Morphol., 30(4):1490-1496, 2012.

RESUMEN: La placenta, anexo embrionario propio de los mamíferos placentados, imprescindible para la supervivencia embriofetal, está formada por la zona más superficial del endometrio y el corion, asociado con el saco vitelino o el alantoides, dependiendo de la especie. La placenta provee el intercambio gaseoso y nutricio entre la madre y el feto, secreta hormonas y posee propiedades inmunosupresoras. Existen diferentes criterios para clasificar la placenta; de acuerdo a la distribución de las vellosidades coriales de la placenta: difusa, cotiledonaria, zonaria y discoidal; de acuerdo a las características histológicas de la placenta: epiteliocorial, sindesmocorial, endoteliocorial y hemocorial.

\section{PALABRAS CLAVE: Placenta; Morfología comparada.}

\section{INTRODUCCIÓN}

En los mamíferos el crecimiento y la supervivencia del feto durante su desarrollo dependen exclusivamente de la placenta, conformada por tejidos maternos y fetales. El componente fetal está representado por el corion, el cual de acuerdo al tipo de placentación, está asociado con el saco vitelino o con el alantoides. Por su parte el componente materno está dado por la zona más superficial del endometrio uterino. La placenta forma una verdadera interface entre la circulación materna y fetal, facilitando el intercambio gaseoso y metabólico entre la circulación fetal y materna. Además posee la capacidad de secretar hormonas y producir una barrera entre ambos sistemas inmunes facilitando la supervivencia del feto en el útero.

Funciones de la placenta. Se destacan las funciones más relevantes de la placenta en la Tabla I.
Función de intercambio. La placenta está destinada al intercambio fisiológico entre la madre y el feto, siendo el intercambio gaseoso la función primordial de este órgano, seguida por la absorción de nutrientes y la excreción de productos de desecho. Los diferentes componentes de este intercambio son transportados por difusión simple $\left(\mathrm{O}_{2} \mathrm{y} \mathrm{CO}_{2}\right)$, difusión facilitada y mediante transporte activo altamente selectivo (Watson \& Cross, 2005). Estos pueden variar entre distintos mamíferos, siendo por ejemplo la difusión pasiva el tipo de transporte que adquiere mayor relevancia en roedores (Watson \& Cross).

Existe en la placenta una intensa actividad de intercambio y de síntesis, pasando de la madre al feto sustancias nutritivas, tales como oxígeno, agua, glucosa, lactato, aminoácidos, ácidos grasos libres, vitaminas, electrolitos,

Tabla I. Funciones principales de la placenta.

- Permitir el intercambio de gases y nutrientes entre madre y feto.

- Elaborar hormonas: gonadotrofina coriónica (mantiene el cuerpo lúteo funcional), progesterona (mantiene la gestación), lactógeno placentario. (promueve el desarrollo de la glándula mamaria).

- Proteger al feto de la respuesta inmune materna impidiendo que éste, sea rechazado como cuerpo extraño.

\footnotetext{
* Programa de Magister en Ciencias Biológicas, Facultad de Medicina, Universidad de Chile, Chile.

** Depto. de Ciencias Básicas Biomédicas, Facultad de Ciencias de la Salud, Universidad de Talca, Chile.

*** Laboratorio de Embriología Comparada, Facultad de Medicina Universidad de Chile, Chile.

**** Facultad de Medicina, Depto de Pediatría. Universidad de La Frontera, Chile.
} 
hormonas, anticuerpos, algunos medicamentos y algunos patógenos tales como virus (VIH). Del feto a la madre, en cambio, pasan productos finales del metabolismo, tales como urea, anhídrido carbónico. (Gudea et al., 2004).

Función endocrina. La placenta es una estructura carente de inervación por lo cual la comunicación entre madre y feto se establecerse mediante sustancias que viajen vía sanguínea, estas pueden ejercer una acción local actuando en la misma placenta o bien a distancia a nivel uterino o en el mismo feto (Gudea et al.). Estas hormonas juegan un rol importante orientadas principalmente a causar un efecto en la madre y en menor proporción al feto. Las podemos clasificar en dos tipos: peptídicas y esteroidales.

\section{Hormonas esteroidales.}

- Progesterona. Es secretada por el cuerpo lúteo y a partir del segundo mes comienza a ser secretada por la placenta y su producción se ve aumentada durante el transcurso del embarazo. Se sintetiza en la placenta a partir del colesterol; la mayor parte de la progesterona producida pasa a la circulación materna; parte de esta es captada por el feto y se utiliza como sustrato para la síntesis de corticoides fetales. En el útero participan en la formación de las células deciduales, vitales en la nutrición del embrión recién formado.

- Estrógenos tienen efecto proliferativo en tejidos maternos, como por ejemplo aumento de tamaño del útero, mamas y genitales externos; cambios orientados a un normal desarrollo del embarazo (Gudea et al.).

Hormonas peptídicas. Lactógeno placentario es producido por el sinciciotrofoblasto, estimula el desarrollo y secreción de la glándula mamaria (Pérez \& Donoso, 2011), y el crecimiento de órganos fetales y el peso de la placenta (Prieto et al., 2008a).

- Gonadotrofina coriónica (hCG). Es sintetizada tempranamente por el sinciciotrofoblasto. Esta hormona posee una acción a nivel materno semejante al de la hormona luteinizante (LH) hipofisiaria y su función es mantener el cuerpo lúteo funcional; este producirá progesterona, andrógenos y estrógenos entre otras.

Función inmune. Es importante destacar que el embrión es un verdadero injerto para la madre (Aloinjerto tolerado), posee gran cantidad de proteínas extrañas para el sistema inmune materno las cuales son sintetizadas a partir de los genes aportados por el padre, existe por lo tanto, un mecanismo compatibilizador que impide el rechazo, dado principalmente por la producción por parte de la placenta de factores inmunosupresores e inmunomoduladores en estadios tempranos (trofoblasto), además una adaptación en la respuesta inmune materna frente a los antígenos de histocompatibilidad fetal (Moffett \& Loke, 2006).

La morfología de la placenta varía de acuerdo a las especies y las características anatómicas que presenta el tracto reproductivo (pliegues uterinos, carúnculas uterinas, etc.) como también de acuerdo al tipo de implantación presente en cada una (Tabla II).

Tabla II. Tipos de implantación en los mamíferos.

\begin{tabular}{lccc}
\hline & $\begin{array}{c}\text { Día de } \\
\text { implantación }\end{array}$ & $\begin{array}{c}\text { Duración } \\
\text { de } \\
\text { gestación }\end{array}$ & $\begin{array}{c}\text { Tipo de } \\
\text { implantación }\end{array}$ \\
\hline Rata & 5 & $20 \ddot{0}-22$ & Excéntrica \\
Conejo & $7-8$ & 31 & Central \\
Gato & $12-14$ & $60-65$ & Central \\
Bovino & $30-50$ & $275-290$ & Central \\
Cerdo & $11-12$ & $112-115$ & Central \\
Humano & $6-7$ & $225-274$ & Intersticial \\
\hline
\end{tabular}

Clasificación. Un criterio para clasificar la placenta considera el tipo de relación que se establece entre la madre y el feto según el origen vascular. Otro criterio es el anatómico, y un tercero es el histológico.

Clasificación de las placentas según el origen vascular. En los mamíferos la placenta se desarrolla inicialmente como una placenta coriovitelina este tipo de placentación se establece cuando la pared del saco vitelino se une con el corion, este tipo de placenta prontamente experimenta un proceso de involución. En cambio la placenta corioalantoidea se establece cuando se fusiona el alantoides con el corion. La placenta corioalantoidea se constituye tardíamente y es la definitiva. Es un eficiente mediador de los intercambios fisiológicos entre la madre y la cría (Rojas \& Rodríguez, 1987).

Clasificación morfológica de las placentas. Según la forma en que se distribuyen las vellosidades coriales en la placenta, existe la siguiente clasificación anatómica (Tabla III)

Placenta difusa. Las vellosidades y pliegues coriales son de pequeño tamaño y se distribuyen uniformemente en la superficie fetal de la placenta; estas se oponen en íntimo contacto con depresiones o surcos del epitelio uterino. Este tipo de placenta se encuentra en porcinos, equinos, camélidos y cetáceos (Fig.1a, b y c). 
Tabla III, Clasificación de las placentas en los mamíferos, según ubicación de las vellosidades coriónicas.

\begin{tabular}{lll}
\hline Tipo de placenta & Especies & Características de las vellosidades \\
\hline Difusa & Suino, equino & Se distribuyen uniformemente. \\
Cotiledonaria & Bovinos, ovinos, caprinos & Se distribuyen en forma de roseta. \\
Zonaria & Felinos, equinos & Se distribuyen ecuatorialmente en forma de cinturón \\
Discoidal & Humanos, primates, roedores & Se distribuyen formando un disco. \\
\hline
\end{tabular}
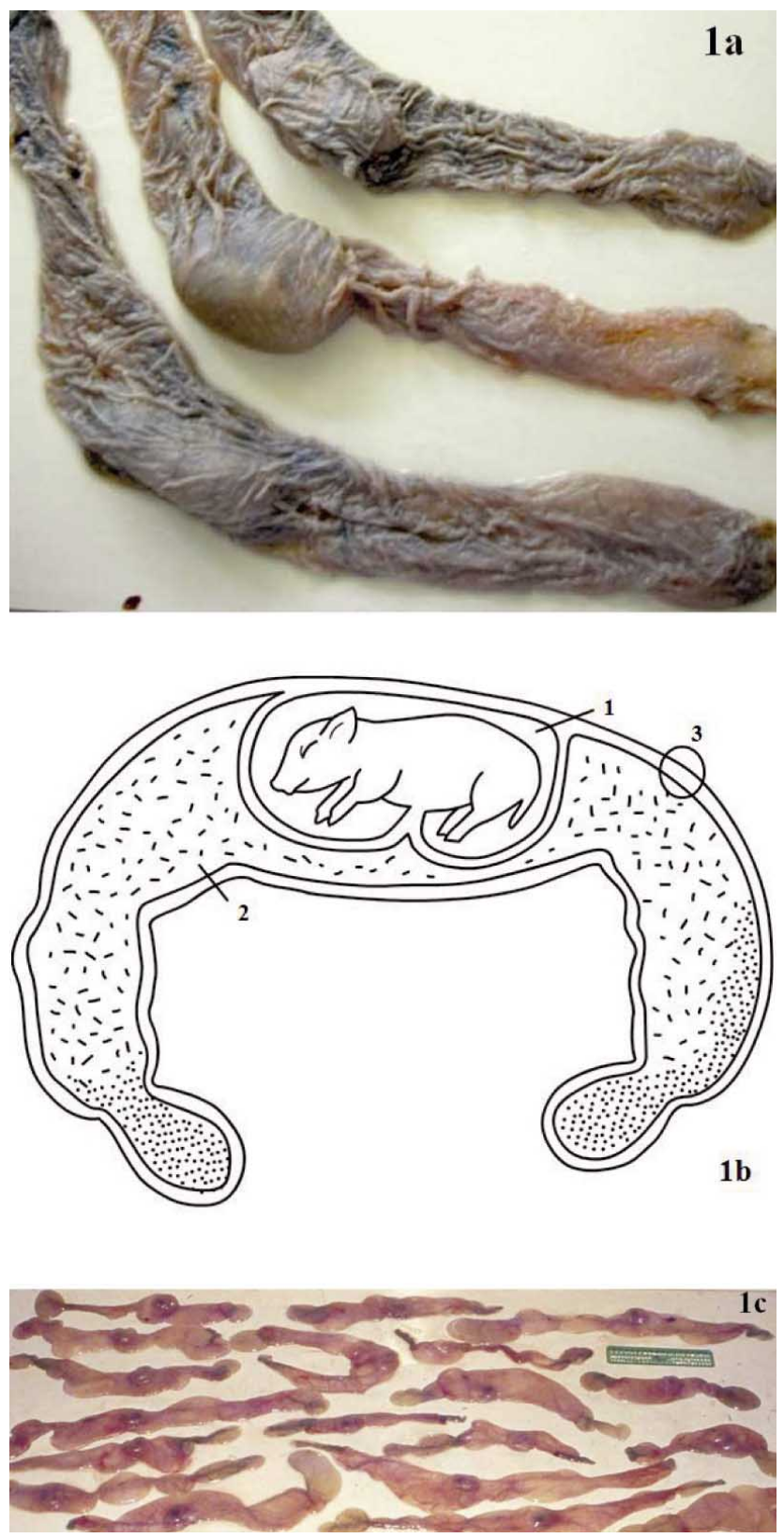

Fig. 1a. Placentas difusas de porcino. Fig. 1b. esquema de placenta de porcino. 1. Cavidad amniótica; 2. Cavidad alantoidea; 3. Alantocorion. Fig. 1c Placentas pertenecientes a una misma hembra de porcino.
Placenta cotiledonaria. Las vellosidades coriales se agrupan en rosetas llamadas cotiledones que se relacionan con las carúnculas endometriales del útero. Se encuentra en rumiantes (bovinos y ovinos). Las estructuras uterinas y coriónicas en conjunto conforman una estructura llamada placentoma. (Fig. 2a, b y c).

Placenta zonaria. La vesícula alantocoriónica es ovoide y está rodeado por una banda o cinturón de vellosidades coriónicas que se dispone ecuatorialmente. Es propia del perro y gato (Fig.3a, b y c).

Placenta discoidal. Las vellosidades del corion (corion frondoso) abarcan un área circular y polarizada. Se encuentra en primates incluyendo a los humanos y en roedores (Figs. 4a y b).

En ovinos, bovinos y caprinos durante las primeras etapas de la placentación se observa que el corion también tiene las vellosidades coriales distribuidas uniformemente en forma similar a los cerdos, pero pronto estas vellosidades coriales se redistribuyen agrupándose en rosetas llamadas cotiledones y dejando otras áreas libres de vellosidades para originar el corion liso. Se sabe que es el contacto del epitelio coriónico con las carúnculas uterinas el responsable de la formación de vellosidades que formarán los cotiledones fetales. La unión constituída por la carúncula uterina materna y el cotiledón fetal se llama placentoma. Estas placentas se llaman cotiledonarias. En las áreas de corion liso entre los cotiledones se encuentran vellosidades muy pequeñas, frente a ellas se opone la mucosa intercaruncular que posee muchas glándulas (Rojas \& Rodríguez).

Clasificación histológica de la placenta. Esta clasificación se basa en el número de barreras que se interponen entre la sangre fetal y la materna, su número máximo es de seis, tres fetales y tres maternos (Fig. 5). Los tejidos fetales son los siguientes: epitelio del corion fetal, tejido mesenquimático fetal y endotelio del capilar fetal. Los tejidos maternos son: epitelio de la mucosa uterina, tejido conjuntivo materno, endotelio de los capilares maternos. 

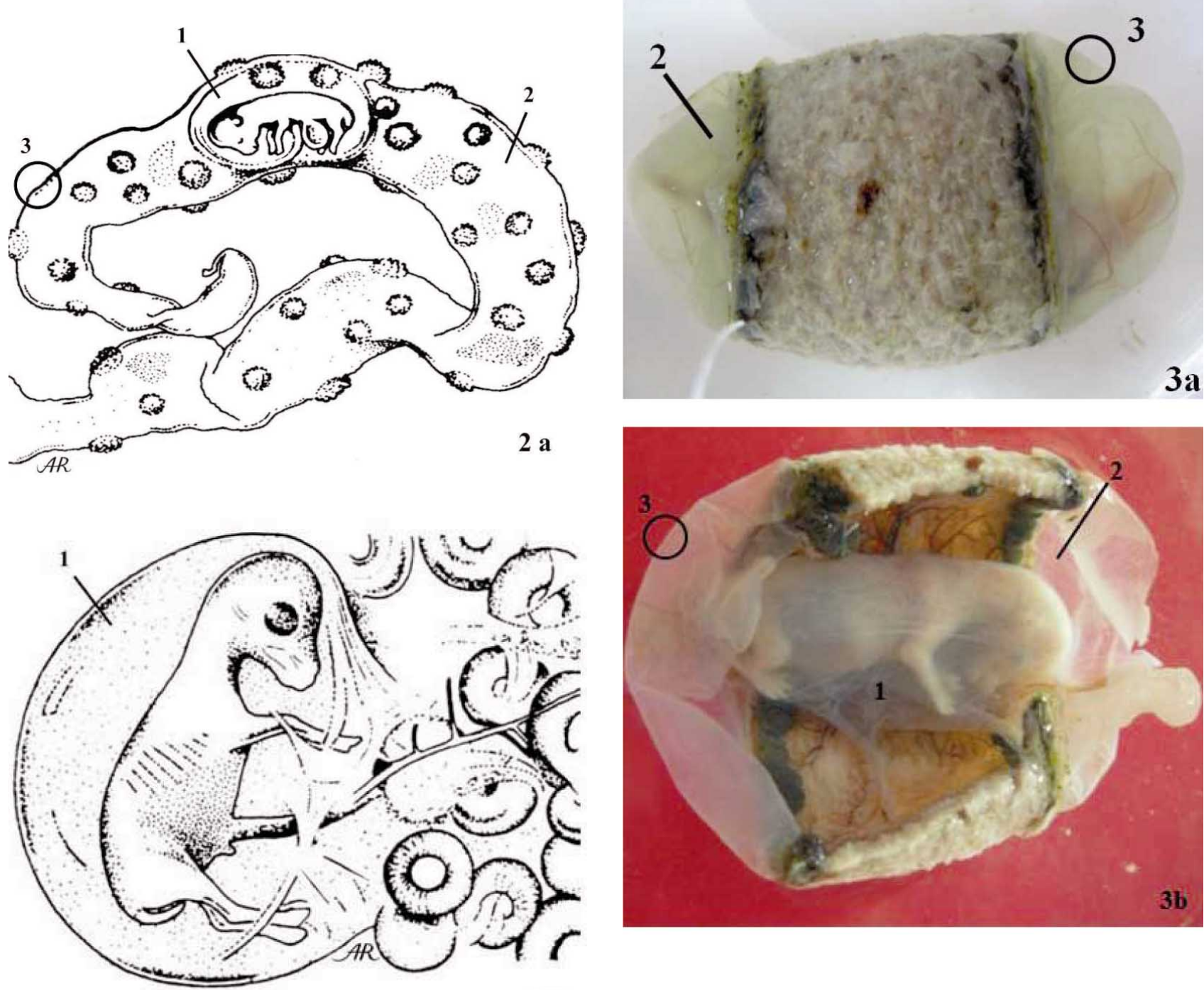

2 b
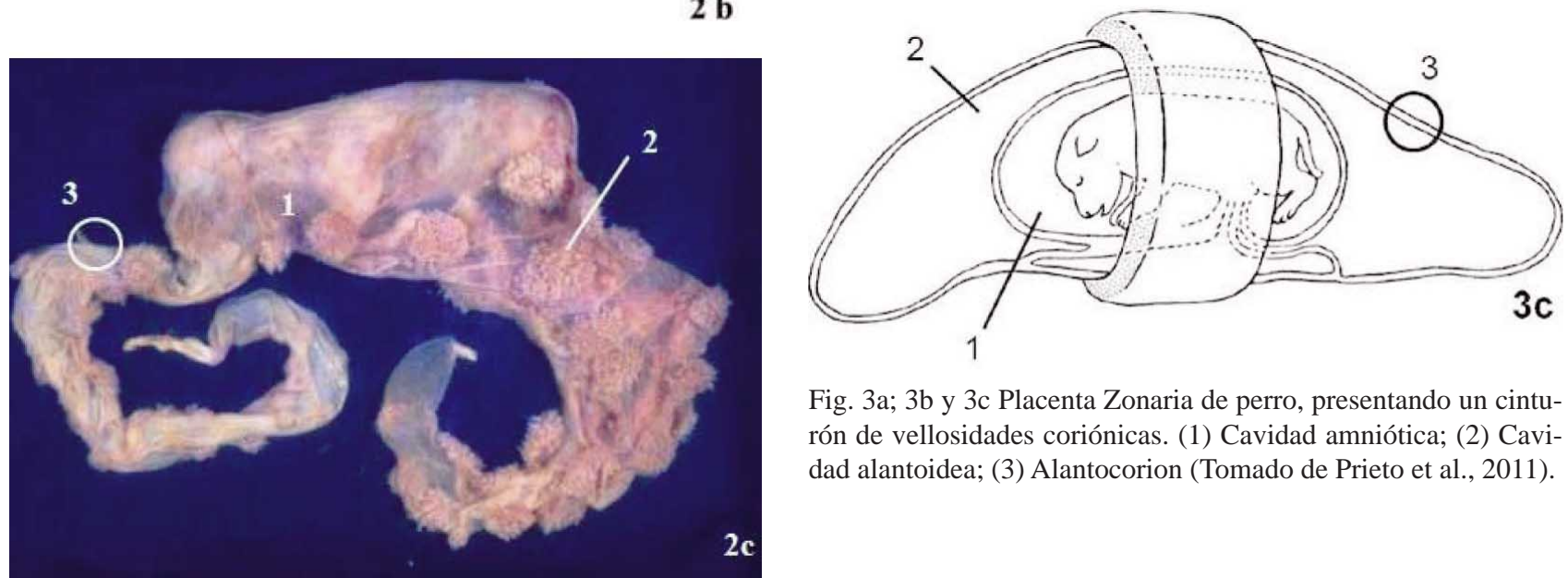

Fig. 3a; 3b y 3c Placenta Zonaria de perro, presentando un cinturón de vellosidades coriónicas. (1) Cavidad amniótica; (2) Cavidad alantoidea; (3) Alantocorion (Tomado de Prieto et al., 2011).

Fig. 2 a. Placenta cotiledonaria esquemática de bovino. 1. Cavidad amniótica; 2. Cavidad alantoidea; 3. Alantocorion. Fig. 2b. Placenta cotiledonaria esquemática de ovino. 1 Cavidad amniótica. Fig. 2c. Placenta cotiledonaria de ovino. (Gentileza Dr. Ángel Rodríguez)

Placenta epiteliocorial. Las vellosidades coriales contactan con el epitelio de la mucosa uterina. Existiendo interdigitaciones entre ambos tejidos. Se encuentra en porcinos y equinos (Dellmann), (Fig. 6a-6b). 

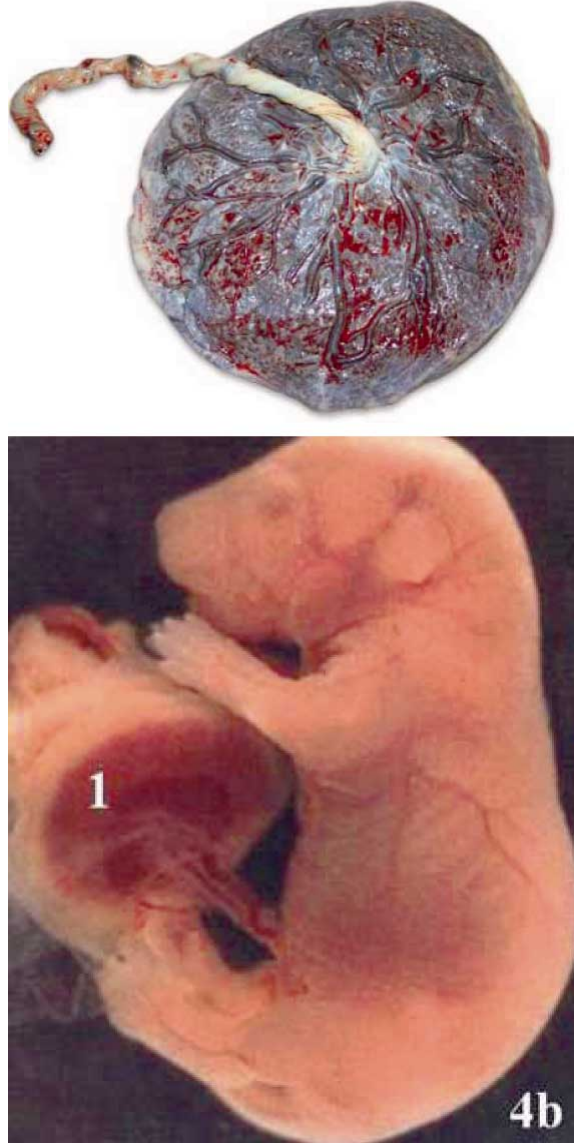

Fig. 4a y 4b. Placenta discoidal humana y de roedor respectivamente. 1. Las vellosidades del corion (corion frondoso) abarcan un área circular y polarizada.

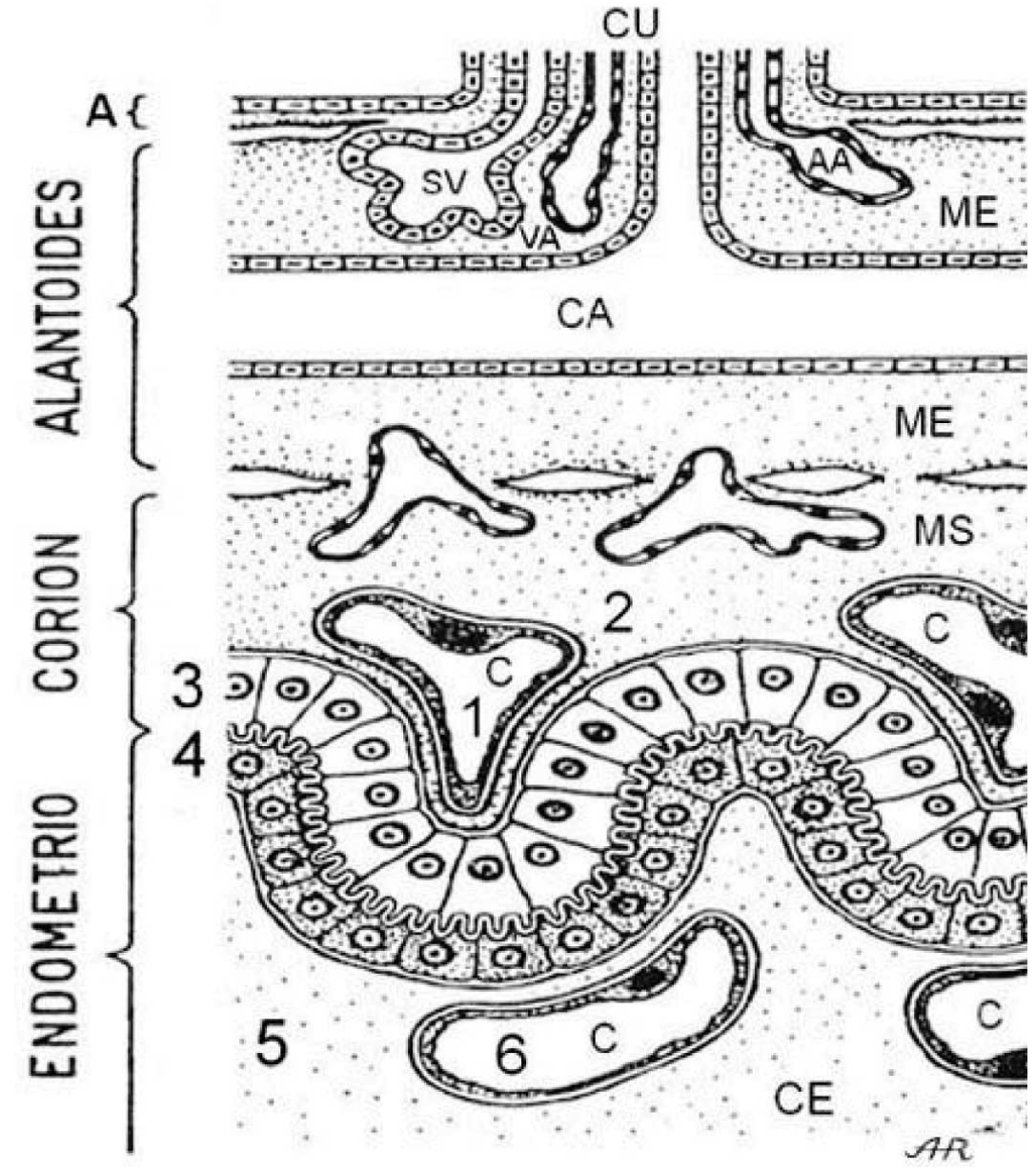

Fig. 5. Esquema de la histología de los tejidos maternos y fetales que conforman la placenta: 1. Endotelio del capilar fetal; 2. Mesénquima fetal; 3. Epitelio del corion fetal; 4. Epitelio uterino materno; 5. Conectivo uterino materno; 6. Endotelio del capilar materno. Gentileza Dr. Ángel Rodríguez.
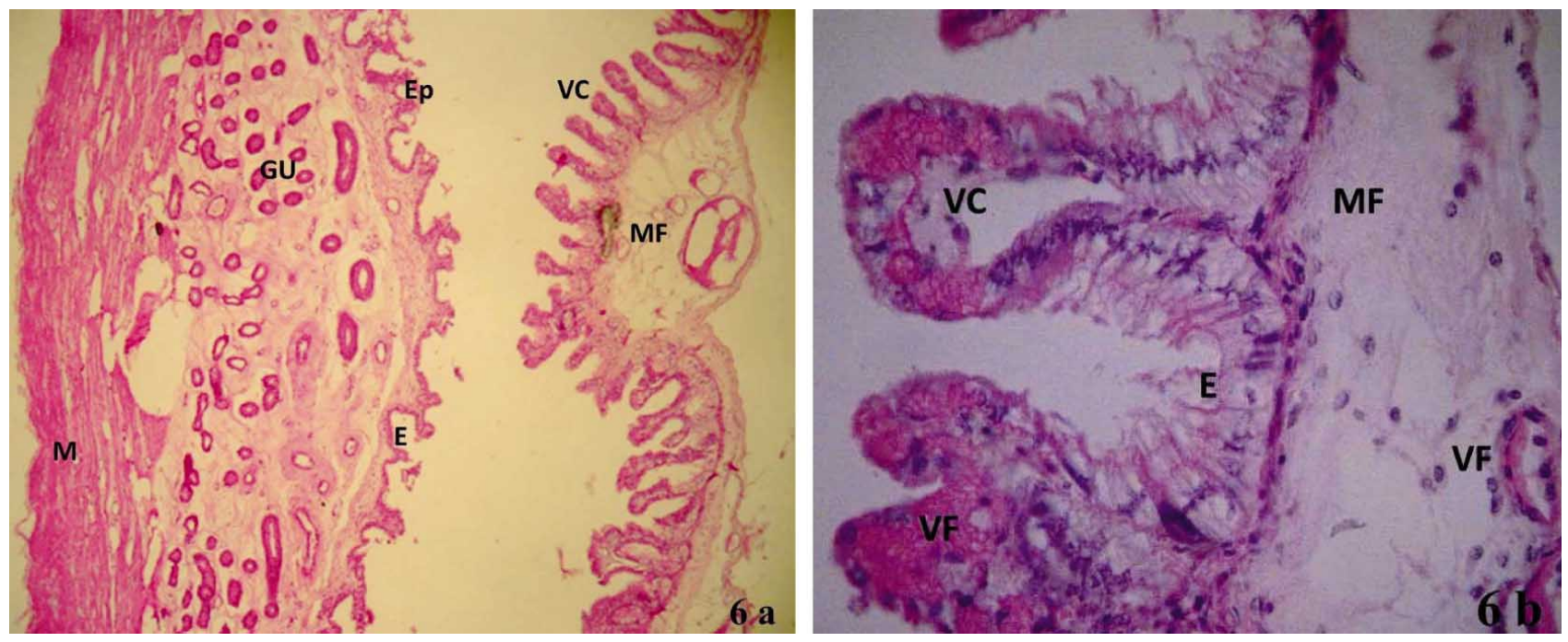

Fig. 6a. Placenta epiteliocorial de porcino. VC. Vellosidad corial; Ep. Epitelio; E. Endometrio; MF. Mesénquima fetal,; GU. Glándulas uterinas. M. Miométrio. 5x. Fig. 6b. Placenta de porcino. VC. Vellosidad corial; E. Epitelio; VF. Vaso fetal; MF. Mesénquima fetal. 10x 
Placenta sindesmocorial. En que el corion contacta con el tejido conectivo materno, falta la capa epitelial. Es la placenta de ovinos y bovinos, aunque debe destacarse que inicialmente la placenta es epiteliocorial (Dellmann), (Fig.7).
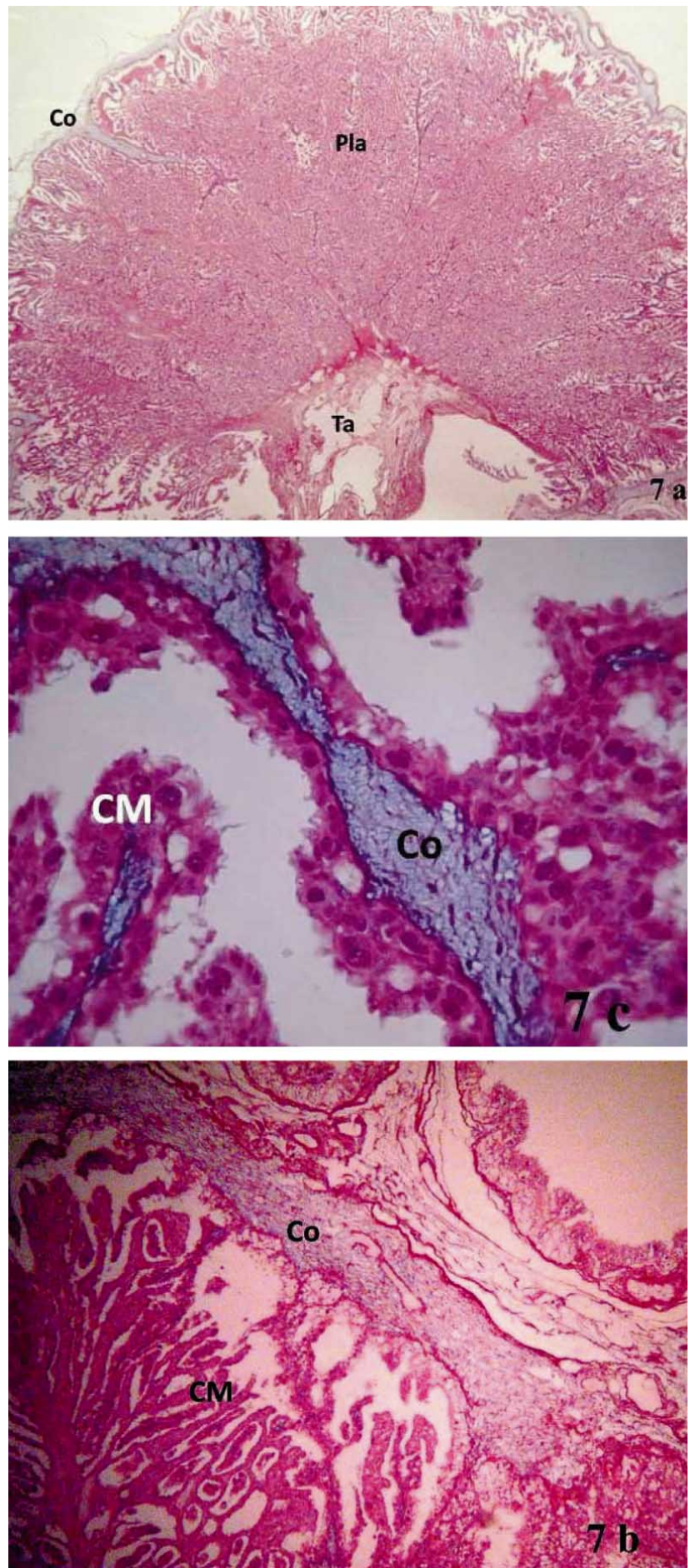

Fig. 7a. Placentoma de bovino. Co. Corion; Pla. Placentoma; Ta. Tallo del placentoma. 5x. Fig. 7b. Placenta sindesmocorial de bovino. Co. Corion; CM. Tejido conectivo materno. 10x. Fig. 7C. Placenta de bovino. 50x.
Placenta endoteliocorial. En este tipo de placenta el corion contacta con el endotelio de los vasos sanguíneos del endometrio. Se encuentra en gato y perro (Perry, 1981), (Fig.8).
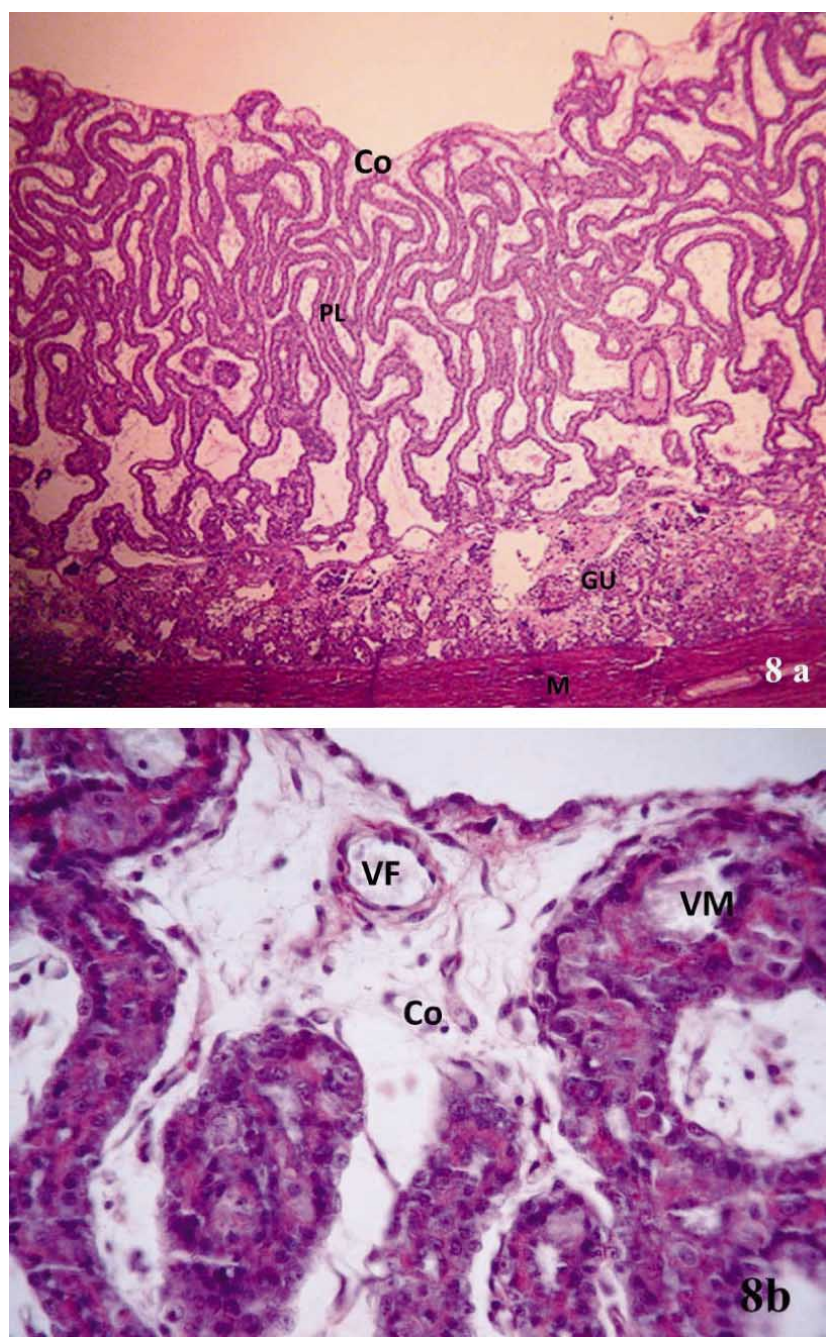

Fig. 8a. Placenta epiteliocorial de gata. (Co) Corion, (PL) Placenta laberíntica, (GU) Glándulas uterinas, (M) Miométrio. 5x. Fig. 8b. Placenta de gata. (Co) Corion; (VM) Vaso sanguíneo materno, (VF) Vaso sanguíneo fetal. 10x.

Placenta hemocorial. Las vellosidades coriales flotan libremente en la cámara hemática, en contacto con la sangre materna. No existen las barreras maternas y de las barreras fetales después de las 20 semanas de gestación sólo queda endotelio y un reducido trofoblasto (lámina sinciciovascular). Se encuentra en la especie humana y roedores, siendo laberíntica en roedores (vellosidades unidas entre sí) y vellosa en humanos (vellosidades no se unen) (Perry), (Fig.9). 


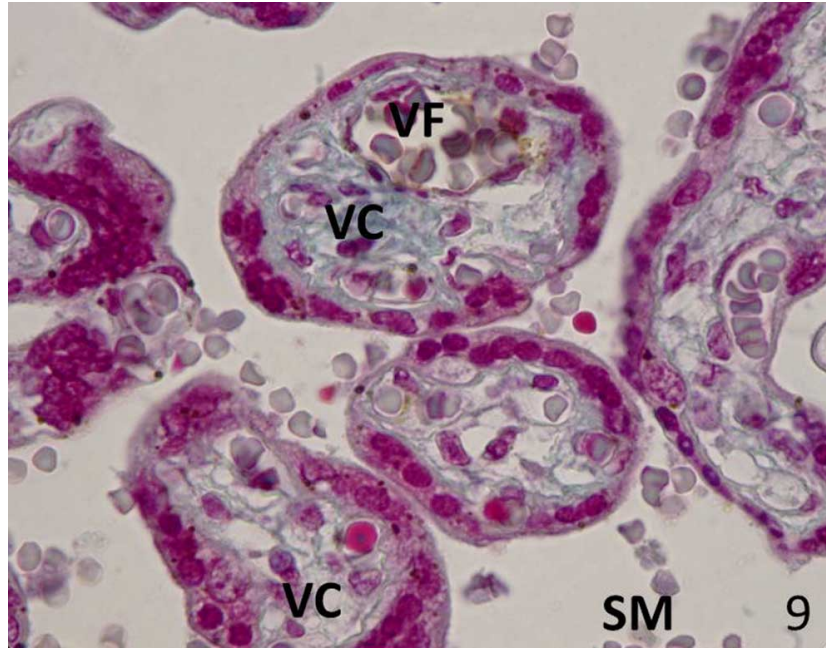

Fig. 9. Placenta hemocorial humana. Se observan vellosidades coriónicas (VC) con vasos fetales (VF) flotando directamente en la cámara hemática de sangre materna (SM). 50x. (Tomado de Prieto et al., 2008b).

\section{AGRADECIMIENTOS}

Los autores agradecen a la Dra. Mariana Rojas R. por el apoyo entregado en la confección de este artículo.

ROA, I.; SMOK, S. C. \& PRIETO, G. R. Placenta; compared anatomy and histology. Int. J. Morphol., 30(4):1490-1496, 2012.

SUMMARY: The placenta is an extraembryonic membrane of placental mammals, essential for embryo survival. It is formed by the most superficial zone of the endometrium and the chorion, associated with the yolk sac or allantois, depending on the species. The placenta provides gas and nutrient exchange between mother and fetus, secretes hormones and has immunosuppressive properties. There are different criteria to classify the placenta; i. e. according to the distribution of the chorionic villi of the placenta: diffuse, cotyledonary, zonaria and discoidal; according to the histological characteristics of the placenta: epitheliochorial, syndesmochorial, endotheliochorial and hemocorial.

KEY WORDS: Placenta; Compared morphology.

\section{REFERENCIAS BIBLIOGRÁFICAS}

Dellman, H. D. Textbook of Veterinary Histology. $4^{\text {th }}$ ed. Philadelphia, Lea \& Febiger, 1993.

Gudea, N. M.; Roberts, C. T.; Kalionisa, B. \& King, R. C. Growth and function of the normal human placenta. Thrombosis Research, 114:397-407, 2004.

Moffett, A. \& Loke, C. Immunology of placentation in eutherian mammals. Nature Reviews Inmunology, 584-94, 2006.

Pérez, S. A. \& Donoso, S. E. Obstetricia. $4^{\text {a }}$ ed. Santiago, Chile. Ed. Mediterraneo, 2011.

Perry, J. S. The mammalian fetal membranes. J. Reprod. Fert., 62:321-35, 1981

Prieto, R.; Smok, C. \& Rojas, M. Experiencias de blog: placenta comparada. Int. J. Morphol., 29(2):432-5, 2011.

Prieto, R.; Matamala, F. \& Rojas, M. Características morfológicas y morfométricas de la placenta de término, en recién nacidos pequeños para la edad gestacional (PEG) en la ciudad de Temuco-Chile. Int. J. Morphol., 26(3):615-21, 2008a.

Prieto, R.; Matamala, F \& Rojas, M. Immunological distribution of the placental lactogene and IGF-1 receptor on free-chorionic villi of the newborns small for gestational age placentae. Int. J. Morphol., 26(4):1029-33, 2008b.

Rojas, M. \& Rodríguez, A. Placenta. En: Embriología para Medicina Veterinaria. Facultad de Medicina, Universidad de Chile, 1987.

Watson, E. D. \& Cross, J. C. C. Development of structures and transport functions in the mouse placenta. Physiology, 20:18093, 2005.

Dirección para correspondencia:

Dr. Ignacio Roa Henríquez

Depto. de Ciencias Básicas Biomédicas

Universidad de Talca

Avenida Lircay $s / n$

Talca

CHILE

E-mail: iroa@utalca.cl

Recibido : 17-02-2012

Aceptado: 28-07-2012 